\title{
DESIGN AND OPTIMIZATION OF PV/DIESEL HYBRID POWER SYSTEM IN A HOTEL
}

\author{
Y. GARCIA ${ }^{1}$, O. DIAZ ${ }^{2} \&$ R. GUZMAN ${ }^{3}$ \\ ${ }^{1}$ Universidad de Cundinamarca, Colombia. \\ ${ }^{2}$ Universidad Nacional de Colombia, Colombia. \\ ${ }^{3}$ Universidad Pontificia Bolivariana, Colombia.
}

\begin{abstract}
Electric power is a necessity for the development of a society, without it would be impossible to see the world as we actually know. Its use is closely related to modern life and human development. Renewable energy is a good alternative for energy supply in regions where conventional power networks are absent or service quality is intermittent. The importance of these renewable energy sources lies in their lower emissions of carbon dioxide (CO2) to atmosphere and the reduced dependency on raw materials for importation and transport for power generation. Renewable energy is becoming economically competitive in the short to medium term. Hybrid power systems is a novel approach recently gaining popularity, since they combine multiple sources of renewable energy such as solar, wind, mini hydro-power, and also could include conventional generators as support. This combination allows the optimization of the power generation system by reducing emissions from the petroleum and coal based energy sources.

This paper presents a pilot hybrid power system design for the power supply in the hotel 'La mansion' in the town of Acacias, Meta (Colombia). Simulation and optimization were based on a computer program known as HOGA educational version 2.2, which initially considered economic parameters associated to photovoltaic system such as: overall power, replacement cost and operation and maintenance costs, as well as all powers to consider in the simulation. The main purpose is to present an alternative power source in the hotel located in an area with high rates of power outages, and gradually include photovoltaic solar power combined with conventional energy supply, to meet the energy demand when the peak consumption periods occurs during power outages from the power grid.

This paper confirmed that hybrid power systems are a good energy supply alternative as auxiliary small power systems because they are capable of supplying the power demands during power grid outages or even in total absence of the power grid. Simulations showed that the combination of diesel and solar photovoltaics is a good alternative to meet lighting power demand in the hotel 'La Mansion', even in night hours thanks to the battery storage.
\end{abstract}

Keywords: HOGA, hybrid systems, optimization, renewable energy.

\section{INTRODUCTION}

Electric power is a necessity for the development of a society, without it would be impossible to see the world as we actually know. Its use is closely related to modern life and human development. Renewable energy is a good alternative for energy supply in regions where conventional power networks are absent or service quality is intermittent. The importance of these renewable energy sources lies in their lower emissions of carbon dioxide (CO2) to atmosphere and the reduced dependency on raw materials for importation and transport for power generation. Renewable energy is becoming economically competitive in the short to medium term.

Hybrid power systems is a novel approach recently gaining popularity, since they combine multiple sources of renewable energy such as solar, wind, mini hydro-power, and also could include conventional generators as support [1]. This combination allows the optimization of the power generation system by reducing emissions from the 'oil based energy sources' including gas or coal. These hybrid power systems can be used in regions where the power 
networks have low availability or where power outages are frequent; its use has been proven successfully for remote and inaccessible areas [2].

For hybrid power systems it is important to choose a good combination of components and a good strategy, in order to have a economically and technically reliable system for a extended time [3]. What is sought is a balance that reduces the use of expensive resources that lead to large investments with high rates of return, while avoiding interruptions on the power supply. Weather and resources availability, such as radiation in the case of solar power and wind in the case of wind power, can influence the use of a renewable source or another.

There are many applications for hybrid systems optimization, one of the most used is called HOMER (Hybrid Optimization of Multiple Energy Resources), developed by NREL [4]. This software works by selecting a number of possible combinations of solar PV modules, batteries and inverters. The disadvantage of this tool is that only provides generated power, and for recent works it is used as a tool for cost optimization [5]; however, it does not provide the optimal configuration of the PV modules and then it took a long time for the solution [6].

Another application is HOGA (Hybrid Optimization by Genetic Algorithms), a software developed by Rodolfo Dufo-Lopez [7] as a result of his doctoral thesis. It can optimize power systems with multiple combinations such as wind, solar, fuel cells, small hydropower, diesel and gasoline generators, using genetic algorithms for the optimization result. One of the main advantages of this software is that it accurately calculates the optimum configuration: it shows the type and number of PV panels, the type and number of batteries, the power inverter, output power of the diesel generator and the optimal control strategy for cost minimization.

This paper presents a pilot hybrid power system design for the power supply in the hotel 'La mansion' in the town of Acacias, Meta (Colombia). This hotel is located on the coordinates N3.987900, W73.766222, a map view is shown in the Figure 1, and a screen view is shown in the Figure 2. This hotel was selected mainly because the power failure rate in this hotel is high (around 5 power outages / month, with a outage mean duration of $12 \mathrm{~h}$ ), causing significant economic losses. Another reason is that the solar resource is quite abundant in this region ('Los Llanos' region in spanish), so it's an ideal location for solar photovol-

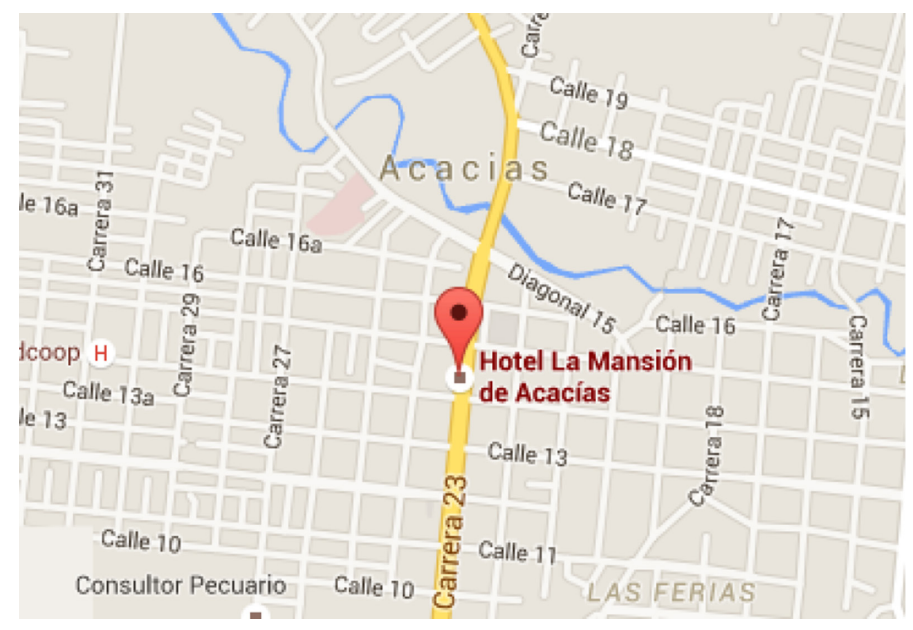

Figure 1: Map location of the hotel 'La mansion'. 


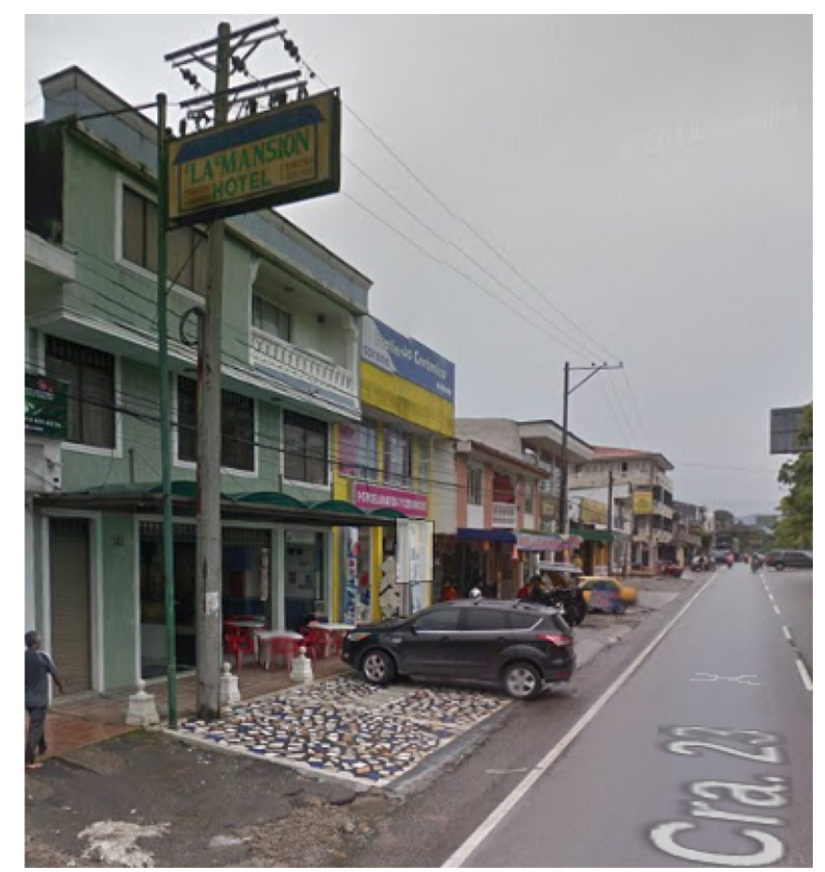

Figure 2: Street view of the hotel 'La mansion'.

taic generation. Finally, this project will help the promotion of renewable energies and sustainable development in this region, and also contributes to the mitigation of climate change.

The main purpose of this paper is to present the project which an alternative power source is used in the hotel, and gradually include photovoltaic solar power combined with conventional energy supply, to meet the energy demand when the peak consumption periods occurs during power outages from the power grid.

\section{MATERIALS AND METHODS}

One of the most important parameters in the design and implementation of hybrid power systems that include renewable energy sources is the availability of energy resources; for instance, for solar PV the resource is the average radiation in the area. Another important parameter is the power demand profile. The software simulates a full year of operation and considers the same lifetime for every year; the simulation variables are defined for hourly intervals by making the assumption that the system is stationary in one-hour periods, thus the variables remain constant during these time intervals.

The study is based on the power load profile (for the reception hall and common areas) of the hotel 'La Mansión' in the town of Acacias. The outline of the simulated system with HOGA is shown in Figure 3.

\subsection{Power consumption profile}

In the hotel 'La Mansióon' the load is distributed by type and use, as seen in Table 1. This estimated profile was done by studying the consumption history of the hotel, as well as the 


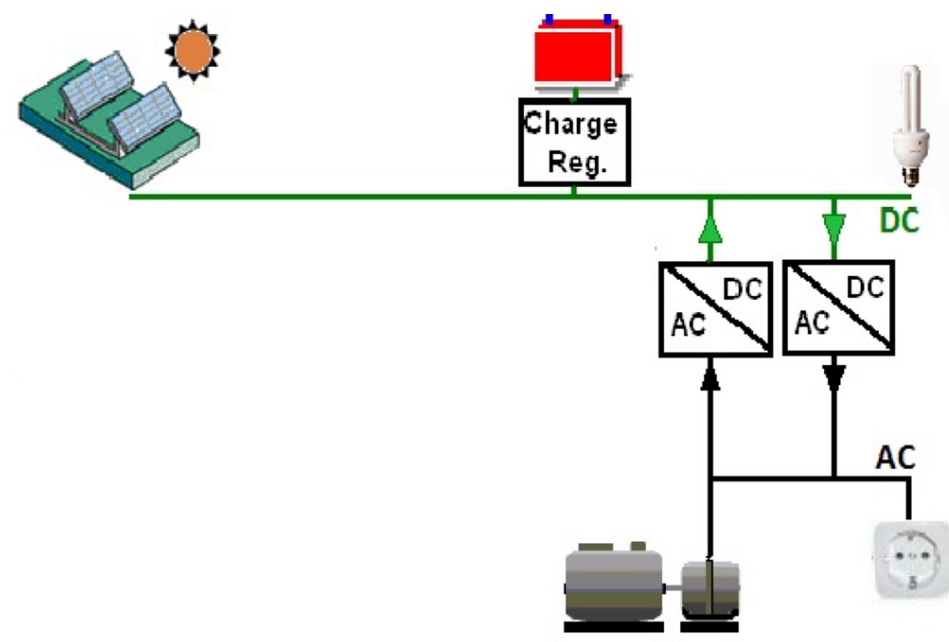

Figure 3: Simulated system using HOGA.

Table 1: Load distribution in the hotel.

\begin{tabular}{ll}
\hline Load type & Consumption $(\mathrm{kWh}$ per day) \\
\hline Lighting & 9.12 \\
Entertainment & 10.89 \\
Food preservation & 94.40 \\
Appliances & 20.55 \\
Air conditioning & 176 \\
\hline
\end{tabular}

load distribution by use, focusing on the priority loads the hotel has during power outages, these are the lighting on the hall, reception and public areas. This lighting has been proposed using low-power LED lamps with power not exceeding the $11 \mathrm{~W}$ and $22 \mathrm{~W}$.

The profile selected for this system corresponds to a $30 \%$ of the daily consumption of lighting loads, with the hall and reception as the priority loads. The daily consumption profile for the proposed system is shown in Figure 4. The Liu Jordan model [8] was selected as a simulation method, because this model considers the solar radiation as the sum of three components: direct radiation, diffuse radiation and reflected radiation. Another important feature of this method is that it contains the climate change for 20 years with a mean uncertainty of $10 \%$.

\subsection{Solar radiation}

Colombia has a privileged geographical position in terms of solar resources, which is abundant throughout the country, with the highest averages of solar radiation in the departments of La Guajira and the Orinoco [9], with average values higher than $4.5 \mathrm{kWh} / \mathrm{m}^{2}$. However, more accurate data from NASA was used to achieve better accuracy for the average solar radiation by horizontal surface. This accurate data is shown in Figure 5, where the monthly 


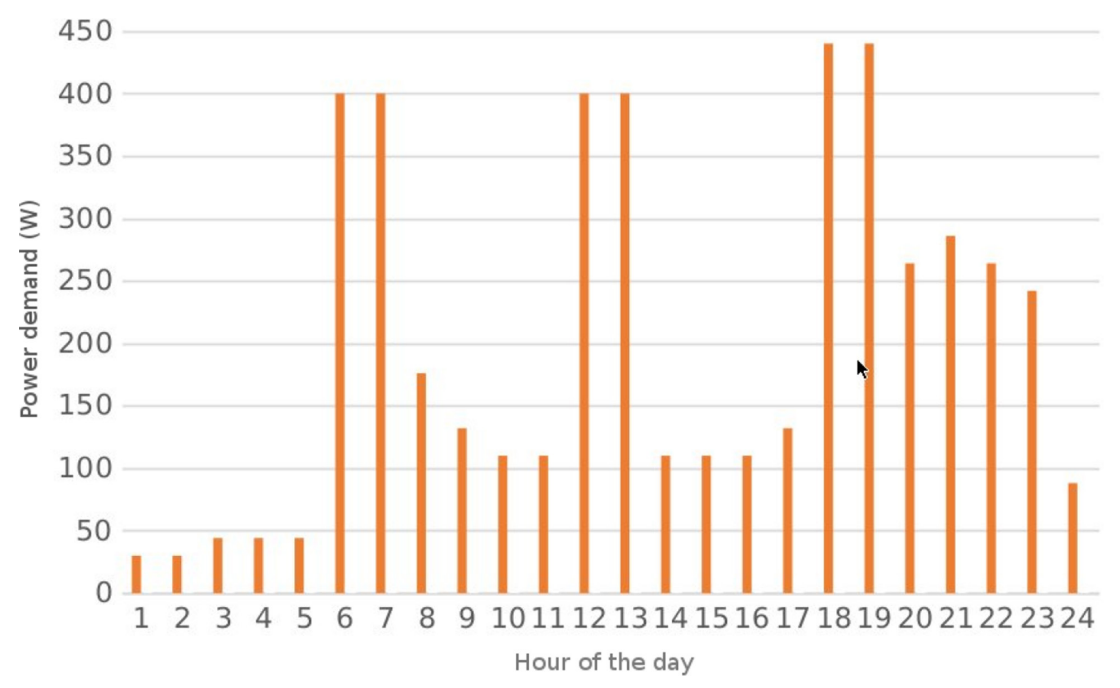

Figure 4: Daily power consumption profile.

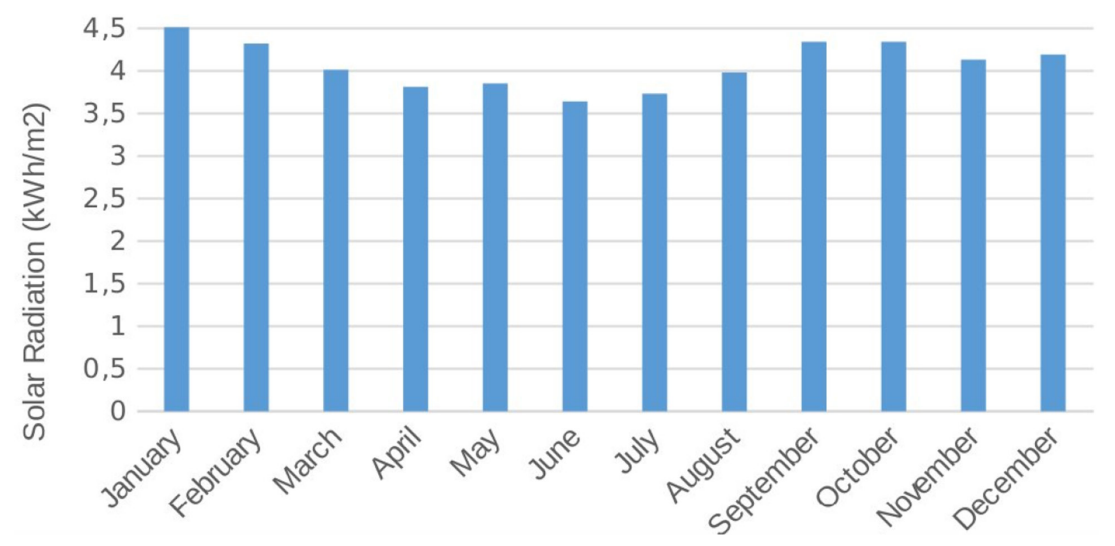

Figure 5: Annual solar radiation for Acacias (Source: NASA).

average supplied by the NASA database is presented [10]. The town of Acacias is 523 meters above sea level and it has an average temperature of $25^{\circ} \mathrm{C}$. The calculated average radiation is $4.07 \mathrm{kWh} / \mathrm{m}^{2}$.

The optimum tilt is not a critical parameter in areas where there are no calendar seasons such as Colombia; however, to have the maximum energy capture by the photovoltaic array the tilt was estimated at $13^{\circ}$ [11]. The ground reflectivity index used is 0.2 .

\section{RESULTS AND DISCUSSION}

The HOGA software delivers an optimal solution, offering the best system possible and an optimal control strategy. The mono-objective mode is the default selected optimization mode, in which the program searches for the most economical solution over the project lifetime, estimating the more favorable Net Present Value (NPV). The best solution resulted in a combination of two panels in series with nine in parallel, with a rated power of $100 \mathrm{Wp}$ each, 12 batteries in series with one battery in parallel with a capacity of $390 \mathrm{Ah}$ and an 1,9 kVA AC generator. 
Table 2: Optimization results.

\begin{tabular}{|c|c|c|c|c|c|c|c|}
\hline Gen. & NPV $(€)$ & $\begin{array}{l}\mathrm{CO}_{2} \\
\text { Emissions } \\
\text { (kg/year) }\end{array}$ & $\begin{array}{l}\text { Energy cost } \\
(€ / \mathrm{kWh})\end{array}$ & $\begin{array}{l}\text { PV Power } \\
\text { (W) }\end{array}$ & $\begin{array}{l}\text { Inverter } \\
(\mathrm{W})\end{array}$ & $\begin{array}{l}\text { Energy not } \\
\text { consumed } \\
\text { (kWh/year) }\end{array}$ & $\begin{array}{l}\text { Battery } \\
\text { capacity (Ah) }\end{array}$ \\
\hline 1 & 26444.40 & 102.43 & 0.71 & 1,800 & 1,800 & 0 & 270 \\
\hline 2 & 26360.02 & 115.78 & 0.70 & 2,400 & 1,800 & 0 & 390 \\
\hline 3 & 26928.21 & 147.66 & 0.70 & 1,800 & 1,800 & 0.09 & 180 \\
\hline 4 & 26284.22 & 155.47 & 0.70 & 1,600 & 1,800 & 2 & 550 \\
\hline 5 & 26728.88 & 127.65 & 0.70 & 2,000 & 1,800 & 0 & 180 \\
\hline 6 & 26153.99 & 106.79 & 0.70 & 2,000 & 1,800 & 0 & 550 \\
\hline 7 & 25922.18 & 109.76 & 0.69 & 2,200 & 1,800 & 0 & 390 \\
\hline 8 & 25918.86 & 165.26 & 0.69 & 1,600 & 1,800 & 2.11 & 390 \\
\hline 9 & 25730.30 & 101.35 & 0.69 & 1,800 & 1,800 & 0 & 550 \\
\hline 10 & 25534.82 & 104.87 & 0.68 & 2,000 & 1,800 & 0 & 390 \\
\hline 11 & 25514.44 & 100.31 & 0.67 & 1,800 & 1,800 & 0 & 390 \\
\hline
\end{tabular}

Optimization data are shown in Table 2, being generation 1 the one with the best system performance. Peak loads can be almost covered entirely by the photovoltaic system, being the stored energy in the batteries a key factor to cover peak loads in the absence of solar radiation (see Figure 6).

This reduces the start and stop cycles in the diesel generator [12].

Battery features used in simulation are shown in Figure 7, with a discharge depth of $25 \%$ up to 5,000 cycles. The battery used is tubular lead-acid type with a lifespan between 15 and 20 years.

The evolution of the NPV observed for 10 generations is shown in Table 2. The better performance case as determined optimum obtained a NPV of $€ 25,514.44$. Based on these results, a cost analysis was done with current market prices, the results are shown in Table 3.

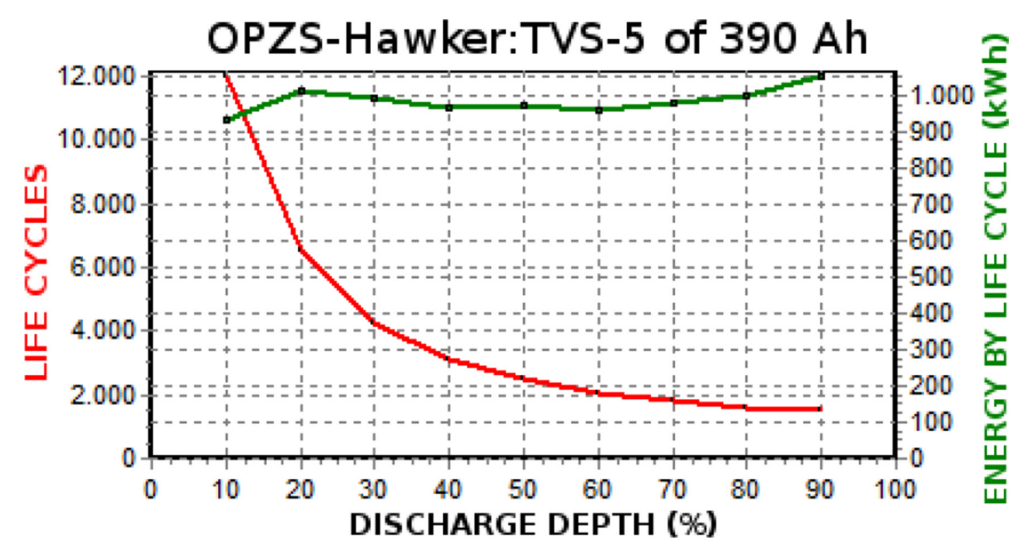

Figure 6: Simulation results: required values for battery charge and battery state (Source: HOGA). 


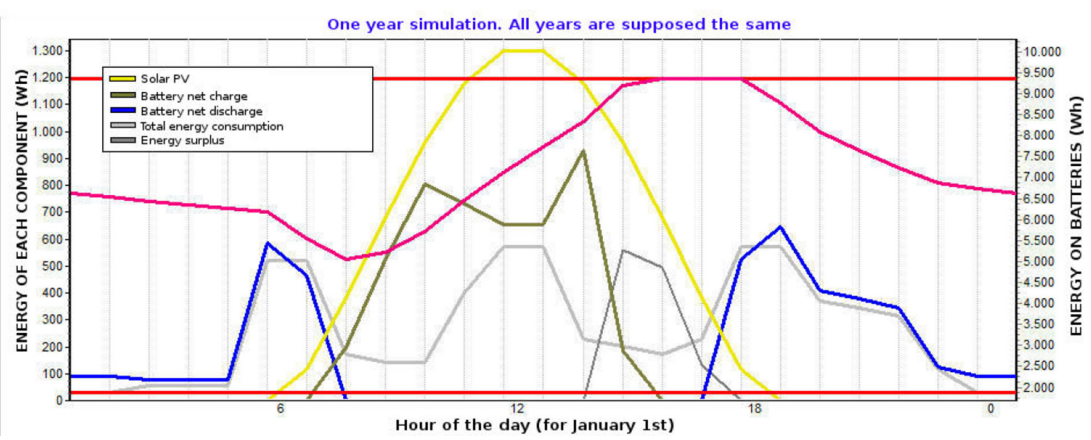

Figure 7: Battery used in simulation (Sources: HOGA).

Table 3: Cost analysis for the hybrid system.

\begin{tabular}{llll}
\hline Equipment & Qty. & Unit price & Total price \\
\hline Solar panel & 18 & $€ 110$ & $€ 1980$ \\
Battery & 1 & $€ 170$ & $€ 170$ \\
Inverter and charger & 1 & $€ 1500$ & $€ 1500$ \\
Installation and Maintenance & - & - & $€ 800$ \\
AC Diesel generator & - & - & $€ 800$ \\
Total: & & & $€ 5250$ \\
\hline
\end{tabular}

\section{CONCLUSIONS}

This paper confirmed that hybrid power systems are a good energy supply alternative as auxiliary small power systems because they are capable of supply the power demands during power grid outages or even in total absence of the power grid. Simulations showed that the combination of diesel and solar photovoltaics is a good alternative to meet lighting power demand in the hotel "La Mansion", even in night hours thanks to the battery storage.

The HOGA simulation tool offers a solution to all possible combinations of power generation and allows the designer to be more accurate on the system configuration for the solar photovoltaic panels (such as number, arrangement and optimal inclination), batteries (such as type, number and arrangement), and some other benefits that other simulation software do not have. It also reduces the use of diesel fuel by decreasing the operation of conventional generators, and also encouraging the gradual use of renewable power sources such as solar photovoltaics.

\section{REFERENCES}

[1] Lakhoua, M.N., Walid, N. \& Atef, C., System analysis of a hybrid renewable energy system. International Journal of Electrical and Computer Engineering (IJECE), 4(3), pp. 343-350, 2014.

http://dx.doi.org/10.11591/ijece.v4i3.5880

[2] Gómez, M.F., Universal electricity access in remote areas: Building a pathway toward universalization in the Brazilian Amazon, Ph.D. thesis, KTH Royal Institute of Technology, Stockholm, Sweden, 2014. 
[3] Perez-Ramirez, R., Perez-Lopez, A. \& Martínez-Arremilla, J.C., Optimización de sistemas híbridos de energía para la electrification rural de comunidades indígenas de mexico. Ingeniería Agrícola y Biosistemas, 3, pp. 33-39, 2011. http://dx.doi.org/10.5154/r.inagbi.2010.10.017

[4] National Renewable Laboratory, Hybrid optimizaciíon model for electric renewable, available at: http://www.nrel.gov/analysis/models_tools.html, Last access on January 2015.

[5] Muñoz, Y., Guerrero, J. \& Ospino, A., Evaluation of a hybrid system of renewable electricity generation for a remote area of colombia using homer software. Tecciencia, 9(17), pp. 57-67, 2014. http://dx.doi.org/10.18180/tecciencia.2014.17.6

[6] Dufo-Lopez, R. \& Bernal-Agustín, J.L., Design and control strategies of pv-diesel systems using genetic algorithms. Solar Energy, 79(1), pp. 33-46, 2005. http://dx.doi.org/10.1016/j.solener.2004.10.004

[7] López, R.D., Dimensionado y control óptimos de sistemas híbridos aplicando algoritmos evolutivos, Ph.D. thesis, Universidad de Zaragoza, 2007.

[8] Liu, B.Y. \& Jordan, R.C., The interrelationship and characteristic distribution of direct, diffuse and total solar radiation. Solar Energy, 4(3), pp. 1-19, 1960. http://dx.doi.org/10.1016/0038-092X(60)90062-1

[9] Unidad de Planeaciíon Minero Energíetica UPME, Atlas de radiaciíon solar de colombia, available: http://www.upme.gov.co, Last access on September 2014.

[10] NASA, Surface metereology and solar energy, available: https://eosweb.larc.nasa.gov/ sse, Last access on November 2014.

[11] Nossa, J.P. \& Romero, E., Diseño de un sistema fotovoltaico aislado para el hotel la Mansion de Acacias (Meta), Master's thesis, Universidad de Cundinamarca, Fusagasugía, Colombia, 2014.

[12] Gudelj, A. \& Krcum, M., Simulation and optimization of independent renewable energy hybrid system. Transactions on Maritime Science, 2(01), pp. 28-35, 2013.

http://dx.doi.org/10.7225/toms.v02.n01.004 